\title{
Can we learn anything from health care in the United States?
}

\section{Matthew HR Anstey \\ MBBS, MPH, FCICM \\ Intensivist \\ Adam G Elshaug $\mathrm{MPH}, \mathrm{PhD}$ Associate Professor and HCF Research Foundation Principal Research Fellow ${ }^{2}$ \\ Lesley M Russell BSc(Hons), BA, PhD Senior Research Fellow ${ }^{3}$}

Susan Wells MBChB, MPH, PhD Senior Lecturer, Health Innovation and Quality Improvement ${ }^{4}$

1 Intensive Care Unit, Sir Charles Gairdner Hospital, Perth, WA.

2 Menzies Centre for Health Policy, Sydney School of Public Health,

University of Sydney,

Sydney, NSW.

3 Australian Primary Health Care Research Institute, Australian National University,

Canberra, ACT.

4 School of Population Health, University of Auckland, Auckland, New Zealand.

matthew.anstey@ health.wa.gov.au

doi: 10.5694/mjal3.11357
A fter studying, researching and working in health care in the United States, we reflect on aspects of the American health care system that Australia and New Zealand would benefit from emulating and aspects that we should avoid.

\section{Things to like about American health care}

\section{Major reform elements of the Affordable Care Act}

The Affordable Care Act is widely recognised for its expansion of population health care coverage, but the major lessons for Australia and New Zealand are reform elements that address the continuum of care. These include: a focus on prevention, public health and health promotion; community needs assessments incorporated into strategic planning for hospitals; ways to improve primary and community-based care; and creation of new models to organise, deliver and pay for health care services. New models include the patient-centred medical home (comprehensive, team-based primary care practices) and accountable care organisations (hospitals and doctor groups joining together to coordinate care and partially share any savings achieved by partnering).

\section{A spirit of innovation}

A wave of innovation has been spurred by the Affordable Care Act, providing funding opportunities (and disincentives) to promote greater systems-level efficiencies in health care and improved health outcomes. The Centers for Medicare and Medicaid Services Innovation Center is an example where the US is dovetailing finance and delivery reform efforts with evaluation to build theory and strengthen practice. Every service delivery or payment model developed and piloted includes a plan of action to ensure that the best practices identified can be spread widely and rapidly. This could be fostered Down Under by creating "improvement challenges" - by using scaleup and spread methods (like the Institute for Healthcare Improvement collaboratives), piloting new multistakeholder initiatives, increasing coordination between payers, or increasing healthy competition between providers, both public and private. ${ }^{1}$

\section{Physician leadership}

The OpenNotes and Choosing Wisely initiatives are examples of physicians leading the way in changing care to be more patient-centred. In many countries, patients can access their medical records, send secure messages and schedule appointments online. OpenNotes has taken this to the next level by allowing patients to read the notes

\section{Summary}

Some aspects of health care in the United States would be beneficial to Australia and New Zealand, but others should be avoided.

- Positive aspects, which should be emulated, include:

v health care reform that is focused on the continuum of care and patient-centred care

trials of new models to organise, deliver and pay for health care services, where quality of care is rewarded over quantity of services

1 an integral view of, and strong support for, health services research as a means of evaluating reforms aimed at improving patient outcomes and systemslevel efficiencies

- physician engagement in reforms - for example, participating in the Choosing Wisely initiative, and trialling and implementing new payment models that are not fee-for-service.

- Negative aspects, which should be avoided, include:

$\checkmark$ increasingly fragmented provider and financing structures (funding provided by state and federal governments, private insurance and out-of-pocket costs) that cause frustration in terms of access and care coordination and increase administrative waste

a an overemphasis on technological solutions, with insufficient acknowledgment of the importance of addressing value in health care

- a focus on hospital and doctor-based health care rather than environmental and social inputs into health.

made by their doctor. ${ }^{2}$ Patients who had read at least one visit note reported feeling more in control and better able to take care of themselves and achieved improved medication adherence. ${ }^{2}$ Such tools pave the way for greater engagement of patients in their health care, increased self-management skills, improved patient safety and better care coordination.

Choosing Wisely started with a handful of specialty societies developing lists of five overused services. ${ }^{3}$ Now more than 50 societies have joined, and over 30 of them announced new lists in early 2014. Some of the measures covered by these lists (eg, not scheduling elective caesarean sections before 39 weeks' gestation or not doing imaging for low back pain unless red flags are present) could lead to dramatic changes in practice. While Australia is making strides towards reducing the use of unnecessary and ineffective treatments, Choosing Wisely has achieved the added benefit of reinvigorating the concept of medical professionalism and responsibility for resource stewardship. ${ }^{4}$ 


\section{Health services research}

The US has long maintained a healthy funding stream for health services research, bolstered in recent years by a US $\$ 1.2$ billion commitment to support comparative effectiveness research. The Agency for Healthcare Research and Quality, the steward for a large proportion of those funds, has built an impressive research infrastructure. For example, under the Evidence-based Practice Centers Program, 11 institutions have contracts to review relevant scientific literature on clinical, behavioural, organisational and financial topics to produce evidence reports and technology assessments and to develop research methods. While Australia and New Zealand do similar work through contracted health technology assessment groups, the scope is narrower and the relative funding is smaller. A unique element of the Evidence-based Practice Centers approach is the inclusion of Future Research Needs Projects, whereby explicit efforts are made to discover questions and problems that are relevant for patients, funders and policymakers.

Australia and New Zealand could also look to emulate work from the newly established Patient-Centered Outcomes Research Institute, which aims to support and share new research that focuses on outcomes that matter most to patients, with a transparent and rigorous evaluation process for new proposals. ${ }^{5}$

\section{Quality improvement and patient safety}

At the most highly regarded medical centres in the US, much focus is placed on quality improvement and patient safety. Encouragingly, Australia has started to provide feedback on quality and safety to the community via the National Health Performance Authority, the MyHospitals website (which provides hospital performance data) and state and national quality commissions. ${ }^{6}$ New Zealand publicly reports on hospital and general practice performance and its Atlas of Healthcare Variation (inspired by the Dartmouth Atlas of Health Care) highlights geographic variation in the provision of care. ${ }^{7}$

However, the breadth and intensity of focus on quality in the US, coupled with real "carrots and sticks" for implementation and public access to information, serve to highlight how far Australia and New Zealand still have to go in tackling this issue. In the US, many hospitals' public internet profiles display their recent patient safety and satisfaction scores, while their internal websites will show number of days since last adverse event. To achieve this level of focus, safety culture needs to be an organisational priority, with clinician leaders partnering with dedicated quality improvement managers in each hospital department. While it must be acknowledged that many US locations are underperformers and that variation in quality of health care is large, organisations focused on quality are gaining traction, notably the Agency for Healthcare Research and Quality, the Institute for Healthcare Improvement and the Leapfrog Group.

\section{Elements of American health care to avoid}

\section{Belief in market-based solutions}

The current political debate over the Affordable Care Act hinges on ideological views about government's role in the provision of health care. Many Americans believe that private health care offers people more freedom of choice and higher quality care than public health care, and that a competitive market is the best way to control costs. However, a competitive market has adverse effects: fragmentation, duplication, little price transparency, vast price differentials, and a marked lack of coordination and desire to share knowledge across health domains. The insurance system is extraordinarily complex, with a bewildering array of plans that differ in terms of coverage, deductibles and copayments. This can be a disincentive to access care; it places an inordinate burden on practices to determine what is covered (and what is not), and it increases administrative costs of health care tremendously. Administrative costs are estimated to make up 31\% of health care expenditure in the private health care system of the US (compared with about $15 \%$ for Australian private health insurance, which is more costly to manage than both US Medicare and Medicare Australia). 8,9

With 80 million Americans underinsured or uninsured, the absence of a safety net means that emergency departments are too often the only source of care and that serious illness can easily lead to bankruptcy. With the US experience as a backdrop, Australia would do well to resist (or reverse) the continuing growth in out-of-pocket costs that has been shown to limit access to services, reduce treatment compliance and increase health disparities. ${ }^{10,11}$

\section{Overemphasis on technological solutions}

A key driver of expenditure growth in the US is the uptake of new health technologies, but technology is not always the answer. The importance of addressing value is rarely acknowledged in the US. Instead, payers at all levels find themselves as passive price takers, to the point where they are legislatively prohibited from calculating any measure of effectiveness relative to cost. ${ }^{12}$ Australia and New Zealand have been vigilant world leaders at espousing the legitimacy of the purchaser's perspective in this regard. After all, the purchaser is the taxpayer and every dollar wasted is a dollar that cannot be put to more effective use. A redoubling of effort is required by our countries in this regard, particularly because free-trade agreements mean that we risk losing the ability to make value-based purchasing decisions with regard to biosimilars (follow-on biologics) and patent-extended pharmaceutical products.

\section{Challenges for health policy in all countries}

\section{Being healthy is not just about health care}

We should remain cognisant that one explanation for why the US performs badly on measures of health outcomes is large inequities in education, wealth and living environment. Health is largely determined by social determinants (such as education, socioeconomic status and lifestyle factors), rather than access to health care services. ${ }^{13}$ In a recent report, the US fared worse than 16 other developed countries in life expectancy, infant mortality, and chronic diseases such as obesity, diabetes, chronic lung disease and heart disease. ${ }^{14,15}$ Australia and New Zealand have no room for complacency. Since the mid 1980s, the proportion of 
the US population living in poverty has hovered steadily at almost $18 \%$. Australia is catching up, having increased from less than $12 \%$ in 1995 to almost $15 \%$ in $2011 .{ }^{15}$ Our countries also have some of the highest rates of obesity in the world - they rank just behind the US. ${ }^{16,17}$

Australia and New Zealand would do well to look to the example of the National Prevention Council in the US, which is driving a whole-of-government approach to preventive health. Funding early childhood development, improving access to healthy foods, improving opportunities for physical activity and thinking about health from a community standpoint are imperatives as we tackle the challenges of obesity and ageing populations.

\section{It is not just hospitals and doctors that matter}

Design-based thinking places the end user at the centre of the process. The end users in health care are the patients, but they are often the last ones to be considered. The focus is too often on individual diagnoses rather than patients. Much more attention needs to be placed on how to integrate long-term care, mental health services and substance misuse services with primary and acute care, and how to support informal care networks.

A lot of care that patients receive is not provided by hospitals or doctors, but the predominant focus of government health policy is medical. Most health care, even for those who are chronically ill or disabled, is provided at home by family and friends, and the economic value of informal care is estimated to far exceed that of formal care ${ }^{18}$ Health care reform efforts should focus on improving both the quality of care that the patient receives and the efficiency of the system. This can only be achieved by thinking across the continuum of care.

\section{How do we pay for value?}

Paying providers per service (a fee-for-service model) makes the accounting simple and makes sense if we just want to encourage the greatest outputs possible. It does not ensure value. Payment and reward systems imperceptibly signal to clinicians what to concentrate on. The US provides an excellent example of what happens when primary care is underfunded; patients receive fragmented care from multiple specialists or emergency departments, and access difficulties increase as "concierge practices" emerge (practices where the patient pays a retainer to the physician in exchange for enhanced access). Reducing the payment imbalance between specialists and primary care providers and between procedural and cognitive services is an important first step in signalling the priorities of the health care system. Future developments should incorporate ways of rewarding health care teams and coordinating care across locations. The US is trialling and evaluating funding mechanisms that move away from the fee-for-service model and funding based on diagnosis-related groups. These funding mechanisms move towards more global diagnosis-related group structures (care coordination as patients move in and out of hospital), bundled care, and integrated system capitation payments models, all linked to quality. We would like to see the medical community in Australia and New Zealand debate and move forward with such options.

\section{Conclusion}

Each year, a farewell dinner is held for outgoing Harkness Fellows in Health Care Policy and Practice, at which they are asked where, given the choice, they would prefer to receive health care. While the predominant answer is their own home country, respondents in 2013 reflected on how impressed they were by the innovative spirit and examples of world-leading excellence they witnessed in the US.

So, while it is easy to write off the US health care system - as it spends almost twice as much on health care per capita as Australia and New Zealand to achieve considerably worse population-level health outcomes on most metrics - some aspects of it are applicable to our countries. The can-do approach certainly is something to take away.

Acknowledgements: Matthew Anstey, Adam Elshaug and Susan Wells were previously supported by Harkness Fellowships in Health Care Policy and Practice from the Commonwealth Fund. The views presented here are ours and should not be attributed to the Commonwealth Fund or its directors, officers or staff. Adam Elshaug holds a National Health and Medical Research Council Sidney Sax Public Health Fellowship (ID 627061) and is supported by the HCF Health and Medical Research Foundation.

Competing interests: Susan Wells has received research funding from the Health Research Council of New Zealand, the Heart Foundation (New Zealand) and Roche Diagnostics. She has a Stevenson Foundation Fellowship in Health Innovation and Quality Improvement.

Provenance: Not commissioned; externally peer reviewed.

1 Schouten LM, Hulscher ME, van Everdingen JJ, et al. Evidence for the impact of quality improvement collaboratives: systematic review. BMJ 2008; 336: 1491-1494.

2 Delbanco T, Walker J, Bell SK, et al. Inviting patients to read their doctors' notes: a quasi-experimental study and a look ahead. Ann Intern Med 2012; 157: 461-470.

3 Cassel CK, Guest JA. Choosing wisely: helping physicians and patients make smart decisions about their care. JAMA 2012; 307: 1801-1802.

4 Elshaug AG, Watt AM, Mundy L, Willis CD. Over 150 potentially low-value health care practices: an Australian study. Med J Aust 2012; 197: 556-560.

5 Selby JV, Beal AC, Frank L. The Patient-Centered Outcomes Research Institute (PCORI) national priorities for research and initial research agenda. JAMA 2012; 307: 1583-1584.

6 National Health Performance Authority. Hospital performance: length of stay in public hospitals in 201112. Canberra: Commonwealth of Australia, 2013. http://www.nhpa.gov.au/internet/nhpa/publishing.nsf/ Content/Report-Download-HP-Length-of-stay-in-public-hospitals-in-2011-12/\$FILE/NHPA_HP_Report_ LOS_Report_November_2013.pdf (accessed Feb 2014).

7 Wennberg JE. Time to tackle unwarranted variations in practice. BMJ 2011; 342: d1513.

8 Cutler DM, Ly DP. The (paper) work of medicine: understanding international medical costs. J Econ Perspect 2011; 25: 3-25.

9 Woolhandler S, Campbell T, Himmelstein DU. Costs of health care administration in the United States and Canada. NEngl J Med 2003; 349: 768-775.

10 Yusuf F, Leeder SR. Can't escape it: the out-of-pocket cost of health care in Australia. Med J Aust 2013; 199 : 475-478.

11 Thomas PE. Reflections on the role of less-than-comprehensive (exclusionary) private health insurance hospital products in the Australian healthcare system. Aust Health Rev 2012; 36: 273-276.

12 Lopert R, Elshaug AG. Australia's 'fourth hurdle' drug review comparing costs and benefits holds lessons for the United States. Health Aff (Millwood) 2013; 32: 778-787.

13 Schroeder SA. Shattuck Lecture. We can do better - improving the health of the American people. NEngl J Med 2007; 357: 1221-1228.

14 Woolf SH, Aron L, editors. US health in international perspective: shorter lives, poorer health. Washington DC: National Academies Press, 2013. http://www.nap.edu/openbook.php?record_id=13497 (accessed Sep 2013).

15 Cooper R. Inequality is at the core of high health care spending: a view from the OECD. http:// healthaffairs.org/blog/2013/10/09/inequality-is-at-the-core-of-high-health-care-spending-a-viewfrom-the-oecd (accessed Oct 2013).

16 Organisation for Economic Co-operation and Development. Crisis squeezes income and puts pressure on inequality and poverty: new results from the OECD Income Distribution Database. http://www.oecd.org/ els/soc/OECD2013-Inequality-and-Poverty-8p.pdf (accessed Sep 2013).

17 Food and Agriculture Organization of the United Nations. The state of food and agriculture: food systems for better nutrition. Rome: FAO, 2013. http://www.fao.org/docrep/018/i3300e/i3300e.pdf (accessed Feb 2014).

18 Access Economics. The economic value of informal care in 2010. Canberra: Access Economics and Carers Australia, 2010. http://carersaustralia.com.au/storage/Economic-Value-Informal-Care-Oct-2010.pdf (accessed Sep 2013). 